\title{
Resilience of Somali Migrants: Religion and Spirituality among Migrants in Johannesburg
}

\author{
Jennifer R.F. Sigamoney
}

\begin{abstract}
Various studies have already been done on the mistreatment of migrants and the psychological effects thereof. This study sought to explore the resilience of Somali migrants residing in Fordsburg/ Mayfair, Johannesburg by interrogating how religion and spirituality may have assisted them in coping with their challenges. A qualitative study was undertaken, using purposive sample of ten Somali migrants. In addition, face to face in -depth interviews were undertaken with participants between the ages of 20 and 55 years. The findings of the study indicated that by supporting the resilience of the Somali migrants, religion and spirituality had played a major role. The interesting part is that their culture and religion becomes integral to their migration. In this regard the community has devised relational, cultural, and religious resources that help them navigate their challenges of migrations. Scholars of migration have, in recent decades, developed increasing interest in the processes and practices through which migrants maintain social relationships that connect the places they leave behind and those where they arrive. Religious affiliations and relationships strengthen these relations. This article argues that resilience can be attributed to their religion, spirituality and cultural identity of the Somali community living in South Africa. The article concludes that high levels of resilience can be linked to the improved socio-economic status of Somali migrants in South Africa.
\end{abstract}

Keywords: Migration, resilience, religion, Somalia

\section{Introduction}

For several decades, the people of Somalia have been confronted with severe levels of armed conflict and forced displacement (Ibrahim 2010; Ingiriis 2016). 
Since the civil war outbreak in 1991, about 2 million Somalis emigrated to live in the diaspora, in countries scattered along the route to Europe, North America and South Africa. Communities of Somali migrants have also emerged further afield in Northern and southern Africa and the Middle East (Al-Sharmani 2010). Many Somalis use South Africa as a transit for a third destination (Shaffer 2012). Countries like the United States of America and Canada, as well as countries in Europe appear to be the popular destination countries. Somali migrants are widely dispersed in many countries globally, and they have adapted to live in different environments (Jinnah 2013; Pineteh 2017; and UNHCR 2018). What makes the Somali community in South Africa interesting is that they illustrate their strength by establishing homes and surviving in a foreign country, drawing resilience from their religion and spirituality. Religion and spirituality play an essential role in motivating them to persist in building livelihoods in the face of problems associated with xenophobia. Moreover, they bring with them traditions, values, culture and a sense of community that makes them conspicuous amidst different nationalities.

Shared values and beliefs are regarded as the fundamental pillars that facilitate the process of refugee integration into local communities (Sadouni 2009). The presence of many South African Indian Muslims in Mayfair attracted Somali migrants to establish themselves in the area, because of their common religious identities (Jinnah 2017). Unlike other African Muslim migrants, especially those from West Africa who have settled in non-Muslim areas such as Hillbrow and Yeoville, Somalis have settled in Muslim dominant suburbs such as Fordsburg/ Mayfair in Johannesburg (Sadouni 2009).

The pursuit of refuge and safety, for many migrants, is a life changing process where individuals recognise and build associations through connecting shared meaning and strategies of coping to harness collective and individual resilience. In addition to the individual efforts, an analysis of communal and cultural strategies for coping with physical emotion and mental vulnerabilities brought on by forced migration, help us better understand how such resources are activated and drawn on 'to deal with trauma, and the encounter with and adaptation to the new society' (BenEzer \& Zetter 2015: 303). Apart from the movement of economic migrants searching for a better life, migration processes are generally marked by problems such as human trafficking, poor administration of asylum application, exploitation, and xenophobia. In this regard South Africa, due to significant mixed migration, is said to have developed robust instruments and institutions to deal with humanitarian 
concerns, but that it has poor law enforcement competencies with respect to migration (IOM 2015). As such, the reception of undocumented migrants at border-crossings creates significant challenges, leaving the migrant vulnerable and the system open to abuses. This kind of mobility not only impacts negatively on and overwhelms existing policies and systems, but also affects other policy domains such as human security, public health, and social cohesion (BenEzer \& Zetter 2015).

Migration has become an increasingly contentious and a politicised issue as governments strives to take action to balance the human rights of its citizens, with the obligation to provide protection to refugees, migrants, and asylum-seekers (Abdi 2015; Wellman \& Colema 2011). There are over 1 million Somalis living in the diaspora and remittances are a focal point of the lives of Somalis living abroad. It is estimated that between US\$750 million and US\$1 billion enters Somalia each year, making it the fourth most remittancedependent country in the world, with remittance contributing between $20 \%$ and $50 \%$ of the country's gross domestic product (Hammond 2014).

With a significant diaspora population in the United States, Minneapolis, Minnesota emerged as a preferred destination due to the low cost of living in a smaller town, a healthy economy, and friendliness towards migrants. Also, transnational networks of Somali migrants led to a surge in migration Somali migration into Minneapolis (Horst 2008). Likewise, Lewiston in Maine proved attractive because of the small-town atmosphere and a low unemployment rate (Abdi 2014). Similarly, there is a large Somali diaspora of Somali migrants across Europe. There are significant numbers of Somalis in Scandinavian countries: in 2007 Norway had about 20000 Somalis; Germany, Netherlands, Italy and Britain had smaller numbers; and France and Switzerland had between 1 000-10 000 Somalis (Horst 2009:327). Because Somali migrants experience labour market discrimination in much of Europe, they rely on social security grants to support themselves, which in turn, (a) limits their prospects of regular integration, and (b) fuels anti-immigration sentiments.

According to Sadouni (2009), Somali migrants in Africa have been reluctant to live in refugee camps in Kenya and Uganda, and have instead opted for more varied settlements (Al-Sharmani 2010). According to the UNHCR (2018), Kenya has the largest Somali diaspora community in Africa, although Jinnah (2013) and Shaffer (2012) show that Somali movement and settlement in Kenya must be understood in its broader geo-historical context, insofar as 
many Kenyans and Somalis share common ethnic and language origins, which are divided by colonial borders (Kleist 2008). Thus for most Somalis who leave their country, Kenya is the first and easiest option for refuge (Coy 2017). In contrast, South Africa does not extend comprehensive social security to nonnationals, and only offers limited and selected social assistance to refugees. As such Somalis tend to rely on their social networks for jobs or entrepreneurial opportunities (Kleist 2007). While South Africa assures migrants and asylumseekers basic human rights, such as work, study, and freedom of movement (Sigamoney 2016; UNHCR 2016), they remain vulnerable to xenophobic prejudice from locals who assign their own 'economic misfortunes like poverty, joblessness to the presence of the Somali migrants' (Hickel 2014:108).

Between 2008 and 2016, South Africa experienced regular national and regional cycles of xenophobic violence directed at foreign nationals, and local traders. These acts included looting of shops, verbal abuse, physical violence and murder (Hickel 2014; Ingiriis 2016). As such Somali migrants have had to develop competencies and strategies for learning how to survive in hostile public spaces. In addition to regular visits to mosques for prayers and fellowship to sustain them through trying times, the Somali community also sought assistance from formally constituted cultural associations, such as the Association of the Somali Community and Somali Board located in Fordsburg/ Mayfair (Jinnah 2010). Established migrant networks in Mayfair and Fordsburg proved attractive to those Somalis who were entering the country for the first time (Jinnah 2010), and the presence of Somali-owned cafes, restaurants, and shops, often alongside homes, has created a distinct Somali cultural resonance in the area (Jinnah 2010; 2013).

This article examines personal narratives of migration and resilience as recounted by Somali migrants that live in the Fordsburg/ Mayfair area of Johannesburg. I hope to illustrate how they utilize and incorporate religion and spirituality into strategies of coping in times of adversity and calamity. In particular narratives of their native country and separation from family and friends, sustains memories that help makes sense of their ideas of belonging, and particular social location their host society (Douglas 1991; AlSharmi 2010). This sense of dislocation sees Somali migrants relying on religion and spiritual practices, which they bring from the native country and ultimately serves to sustain them during trying times (AlSharmi 2010). To develop my argument, firstly, I position Somali migration within its historical and political 
context; secondly, I describe my methodology and the data-collection processes. Finally, I analyse and discuss the narratives of religion and resilience as they emerged from the interviews with Somali migrants.

\section{Social, Cultural, Religious and Spiritual Context}

Somali people inhabit the eastern parts of the Horn of Africa and are spread over several countries: Somalia, Djibouti, Ethiopia, and Kenya. They are an ethnically and culturally homogeneous group, distinguished by a shared common ancestry, a strong 'clan' system, a single language ('Somali'), an Islamic (Sunni) heritage and an agro-pastoral tradition (Shaffer 2012). Adogame and Spickard (2010) have noted that as people move, so too do their religions, which suggests that, like for Somalis, religion or mosque is not just an institution or structure for local, but a transnational community of believers (ummah) held together by shared values. This allows Somali migrants to remain connected although they move to and live in different countries, and the mosque becomes the beacon of hope in the direction of their spirituality. Therefore, their socio-cultural and religious associations play such a vital role in migrant's resettlement and resilience in the host country (Sigamoney 2016, 2017), that I have sought to argue for the constitutive meaning of religion and spirituality in building resilience among Somali migrants.

\section{Social Context}

Somalis face constant discrimination and xenophobia from South Africans in their daily lives, which adversely affects their social mobility and opportunities in the country. This physical and economic insecurity compels Somali migrants to live in Mayfair where they feel protected and supported by their networks and ethnic kin. Due to the patriarchal structure of Somali society, men are ascribed leadership positions where they assume control over their families and community, while women are charged with household management and have a limited ability to challenge these arrangements in broader society (Shaffer 2012; Jinnah 2013). There are conflated patterns of participation for women and men in Mayfair, that appear to contradict customary structures, because as changes in economic activities occur, power is reorganized and cultural standards are adjusted. In effect, for Somalis, these relationships are enmeshed in varying notions of roles and responsibilities, of 
control and leadership, and of religion and culture as they adjust to living in a xenophobic social context. Consequently, the new arrangements threaten traditional social positions for Somali women and men - a risk many Somalis cannot accept and will contest - as they redefine community support and protection for their new home.

The resilience is evident from the adaptation of different gender roles in the family (Shaffer 2012). While more men than women own businesses in Fordsburg/ Mayfair area (Sigamoney 2016), women increasingly participate in trading such as street vending, jewelry trade, cloth retailing, tailoring, and restaurants. According to Shaffer (2012) and Sadouni (2009), Somalis attribute male domination in business to African cultural (and patriarchal) values and practices that are still strongly embedded in Somali society. Under the pressure of surviving in a new social context more Somali women participate in business, including those previously run entirely by men - resulting in shifting gender roles (Abdi 2015).

Likewise, in hostile social contexts, most Somali migrants prefer to live in neighborhoods inhabited by members of their clan, although this ambition is often limited due to a lack of low-income housing challenging their ability to do so (Sadouni 2009). While it is clear that external pressures are changing Somali social relations as well as family or clan patters, it is difficult to estimate the significance of clan divisions in the diaspora, as Somalis rarely deliberate clan dynamics outside of their communities (Shaffer 2012).

\section{Cultural Identity}

Like most migrant communities, Somalis rely on sustaining transnational connections to help them cope with the challenges of settling in the host country (Vertovec 2009). The majority of Somalis are Muslims, and for that reason Islam plays a very important role in Somali culture and social life (Sadouni 2009). Somali Muslims generally believe that religion cannot be separated from social and political life, because religion informs every action (Pentiah 2017). Additionally, scholars of migration have shown increasing interest in the religious developments and rituals that aid migrants in building social relations that connect their societies of origin and settlement (Kabir 2014; Jinnah 2013; 2017; Pinteah 2017). Derain and Asay (2014) contend that these associations are reinforced by religious institutions, religious specialists, and family members. 
At the same time, Somalis, like other migrants, create community spaces to construct their own cultural identity through a sense of unity, cohesion, shared history, and solidarity (Abdi 2014). The building of a distinct diasporic cultural identity - both as a product of, and response to, cultural dissimilarities with South Africans, and their perception that Somalis are unwilling to integrate into South African society - further complicates the relationship between Somalis and South Africans (Langellier 2010). However, the presence of South African Indian Muslims in Mayfair incentivized Somali migrants to establish themselves in the area because of their shared religious I, dentities (Jinnah 2010). Unlike other African Muslim migrants, especially those from West Africa who settled in predominantly non-Muslim neighborhoods, Somalis aspire to live in Muslim suburbs (Langellier 2010; Sadouni 2009). Thus although Somalis find it difficult to integrate and wish to retain their cultural identity, this is lessened by the shared Muslim identity that transcends cultural or racial difference (Al-Sharmani 2010).

\section{Religion and Spirituality}

In the sociology of religion, scholars have grown increasingly interested in the use of religion in the context of migration, whether to make meaning, cope with anxiety, or build networks of belonging, information, and exchange. Adogame and Spickard (2010), for example, confirm the sentiment that when migrants move, they take their religions with them, while other studies focus on how migrants use of churches and mosques as first place for building social relation in the new society (Settler 2018), while others point to how migrants reproduce religious institutions and practices in various sites of settlement as assertions of cultural and religious identity (Robinson 2013).

Ennis (2011) defines interaction between religion and spirituality as an individual's relationship to the revered or divine, as well as a relation that informs other associations and the meaning of one's own life. While religion signifies practices and beliefs related to a particular dogma system, spirituality may or may not include worldviews, dogmas, and practices. For this reason, Gozdziak and Shandy (2002) suggest that religion can be viewed as the external sign of a spiritual receptiveness, or simply a set of culturally cohesive practices, beliefs, and habits. For this reason, and Gozdziak and Shandy (2002) argue that religion and spirituality are frameworks for dealing with grief, loss, and other aspects of human suffering, all of which migrants might encounter. 
Islam provides the single most stable source of strength and public communal identity for Somalis in the diaspora (McMichael 2002). states that while in Christianity, suffering presents a problem in relation to how a loving God can permit suffering, in Islam suffering is viewed as integral to what it means to be alive. Thus for Somali Muslims, suffering is viewed in light of God's omnipotence, part of His purpose and plan for human 'betterment', that requires submission to God. Generally speaking, in Islam suffering has two purposes: as a form of punishment for sin and as a spiritual test or trial (McMichael 2002). Thus, resilience is attained through pious spiritual practice and submission to the will of Allah, who empowers the Somali believer to resolve their pain and suffering.

\section{Methodology and Theoretical Framework}

In order to understand the strategies and patterns of resilience among Somali migrants in the Mayfair/ Fordsburg area in Johannesburg, I developed a qualitative, phenomenological study as this enabled me to explore the lived experience of the Somali migrants (Giorgio 2009). This article emanates from a larger study, the purpose of which was to explore and understand how the lived experiences of the migrants influenced their resilience. Consequently, a qualitative hermeneutic phenomenological approach was determined to be the most appropriate method to conduct this research (Creswell 2014; Patton 2002). This type of research uses descriptions of experiences to uncover meaning about the phenomenon being examined, by focusing on the perceptions of individuals and their lived experiences, which take place in their natural setting (Lopez \& Willis 2004; Denzin \& Lincoln 2011). The hermeneutic approach is applicable to this study because the researcher is able to reflect on her own 'assumptions, beliefs, and presuppositions as an integral part of the phenomenological interpretive process' (Cresswell 2014; Neuman 2011). The hermeneutic phenomenological approach was the logical choice for thematically analysing experiences into collective themes of persistence in a dynamic, ongoing, and reflective exploration of the phenomenon in order to provide a rich, thick description.

A purposive sampling method was used in the selection of Somali migrants. The inclusion criteria were that participants must be Somali migrants who had lived in the Fordsburg/ Mayfair suburbs for a period of at least five years, and were aged between 20 to 55 years. Among the 10 participants there 
was a chef, students, businessmen, university graduates and restaurant owners with whom I conducted individual, face to face, semi-structured interviews between August and October 2015.

The interviews took place at premises of the Somali Board in Fordsburg (Johannesburg) as this was a familiar space to most participants, and in close proximity to where the majority of them lived. In negotiating the time and place for interviews, I had to be aware Somali migrants feel vulnerable, and that they believed that their dress and language makes them conspicuous. As such, a few participants, such as Shireen, Moosa and Abdul recounted that 'We don't speak to other nationalities as we are afraid, our culture and language is different'. To mediate such anxieties, I made use of a gatekeeper, a 25-year old student who was completing his studies in Fordsburg/ Mayfair. He assisted me with gathering the participants in the area of Mayfair. Additionally, I used a translator for interviews with Somali participants who were not fluent in English. In total I was able to conduct 10 interviews, with all participants who gave their consent, and I ensured their anonymity through using pseudonyms for the names of people and places, both in this article and in other writings.

A protectionist model guides current scholarship on migration and resilience because it is presumed that migrant experiences are defined by vulnerability and precarity - lives characterized by risk and in need of protection. In the context of Somali migrants, a protectionist model is exemplified by the emphasis on past traumatic experiences (and present post-migration stressors) and mental health problems, such as anxiety or trauma- and stress-related disorders. However, resilience is measured according to the presence of individual or collective resources and assets. For instance, as already stated for Somali migrants, these strengths and benefits may be in the form of religion, spirituality, and culture and community support (Hammond \& Lindely 2014).

According to Richardson (2002) resilience 'is the process of coping with stressors, adversity, change or opportunity in a manner that results in the identification, fortification, and enrichment of resilient qualities or protective factors' (2002:203). Furthermore, authors like Luthar and Cicchetti (2000:857) recognise that 'resilience is a dynamic process wherein individuals display positive adaptation despite experiences of significant adversity or trauma'. Richardson (2002) argues that it has been a challenge that western resilience researchers have fixated on outcomes that privilege individual agency, resourcefulness, and adaptive capacity, at the expense of relational aspects or 
collective practices of resilience in populations. Subsequently, the idea of resilience does not incorporate the cultural traditions, norms and rituals that sustain communities daily (Sharma 2015; Jinnah 2017; Coy 2017).

Despite the lack of agreement pertaining to how to define resilience, there are two main turns: that of the presence of adversity or risks, and, in spite of those risks, the ability to have successful or positive outcomes (Coy 2017; Ungar 2012). In response to significant adversity, whether psychological, environmental, or material, for understanding the strategies of resilience among the participants in this study, resilience is regarded as both the capacity of individuals and communities to navigate their way to health-sustaining resources, as well as the pursuit of feelings of well-being. In this way, I set out to identify situations where the individuals, families, and the cultural or faith community, generate and provide resources and shared experiences that work to sustain Somali migrants in a culturally meaningful way (Luthar \& Cicchetti 2000).

\section{Findings and Discussion}

The data discussed below reflects the experiences of participants that speak to the 'presence of adversity' and strategies towards a successful and positive outcome, despite the presence of hostilities. The rich and thick data shared by Somali migrants brought out several themes, which will be discussed in the next section. To honour their narratives as well present their stories in a theoretical and thematic frame, the discussion will be presented as follows: (a) presence of adversity with respect to discrimination and xenophobia; and (b) narratives of resilience with respect to religion, and gender.

\section{Discrimination and Xenophobia}

Discrimination and xenophobia were cited as common experiences among the participants, who stated that they often experienced discrimination and xenophobia from the South African police force as well as residents of the townships and were consequently robbed of their freedom in South Africa (Coy 2017; Jinnah 2013). It was apparent that the participants were hurt by the discriminatory treatment, as is evident in the following quotes below. The participants highlighted the fact that they had experienced considerable xenophobia from other residents in the areas where they lived. Recent 
anecdotal evidence indicates that Somali migrants living and owning businesses are at the receiving end of criminal xenophobic attacks by the locals. Mr. Abdul stated,

My uncle was shot and killed in the location, Sebokeng. I hide behind the counter with my brother's friend. My brother told him in my language not to tell them about the money, then they shot him, and they sprayed us with spirit (Mr. Abdul).

Mr Moosa added that crime towards Somali migrants is common in and around the Fordsburg/ Mayfair area.

So in 2008 I opened shop in the same place, but xenophobia started, in the same shop, so they take back everything they burnt the shop, they take everything, again we back, the owner said they don't allow any foreigners because these people are robbing you. He refused to give us our fridge for the cold drink, two fridges with the chicken, four fridges, two for the cold drink and two for the chicken, he refused because that fridge belong to us, we can't do anything so we left it... When xenophobia took place in 2015 the shop got looted, so I left the shop was demolished, everything was taken from the shop...my brother opened a shop there; he opened a grocery shop there in 2007...I was working with my brother; selling in the shop he was selling blankets, and shoes (Mr. Moosa).

Looting of Somali businesses is common in the townships and upon analysing the interview data it was evident to me that the migrant population felt under attack. Mr. Dawood also confirmed that looting was common.

When I get the difficulty just the one day of xenophobia, I did not go to school ... because of the xenophobia and the raping and looting. Well, well .... I was very frightened and did not go to school for many days, but my friends told me I will miss school work and the police are on guard in the streets. I thought maybe I must hide in the flat (Mr. Dawood).

The analysis also highlighted participants' difficulties experiences with 
relocation, injury, and, in some cases, death. Mrs. Ebrahim pointed this out to me.

All our shops we close in December because they looted. It because they have xenophobic attitudes towards the foreigners...the only reason Somalis are a target to crime in South Africa is because they do business no other reason. They are robbed and their shops are often looted. My brother was looted and killed in Bloemfontein. The xenophobia affected me, because I had to take my children and go to a safe place. No husband to look after us. No business, no money (Mrs. Ebrahim).

Mr. Suleman claimed that Somali migrants did not place their trust in the police in the township, as they were considered to be corrupt. They reportedly posed as debt collectors, and went into Mr. Selma's home and demanded the takings from his business. He added that the police attacked his brother. From the interview material it is evident that discrimination and xenophobia were common experiences among the participants. In addition, the participants drew similarities between the trauma experienced in Somalia and that experienced in South Africa, although the modes of violence in Somalia and South Africa were different, participants tended to narrate their experiences of xenophobic violence as a familiar way of life. There was a sense of déjà vu, in which xenophobia was normalised. According to Mr. Isaak:

There is no difference between xenophobia and the war in Somalia. When I was leaving Somalia I thought I would live in peace and be free from all sorts of problems if I reached South Africa. But I just found out this country is not different from Somalia (Mr. Isaak).

Mr. Moosa concurs with Mr. Isaak.

I am saying this because all the things that made me to escape from Somalia have happened to me here. I have been robbed, my shop has been burnt and I have been shot. It is bad here but this violence is nothing,

While Mr Moosa agrees with Mr Isaak, he nevertheless appears to suggest that 
his experience in South Africa is not as extreme as it was in Somalia. He concurs that the violence is bad in South Africa, but he does not agree with the statement that there is no difference between Somalia and South Africa.

As such, they agree about the harsh reality of life in South Africa. Having to measure wellbeing in terms the degree or extent of violence, whether in South Africa or Somalia, reveals the consistent precarity of their lives. This signals their resilience. Despite these narratives of incredible trauma and the challenges that Somali immigrants face in South Africa they also spoke with resilience and pride at having progressed as a community in the Fordsburg/ Mayfair area.

\section{Narratives of Resilience}

Resilience is understood as the capacity to anticipate, manage, adapt to, cope with, and recover from risks, and it expresses the capacity of a system to absorb disturbance and reorganise itself so as to retain essential functions, structure, identity and feedback (Richardson 2002) In conceptual terms, the resilience of a household depends on the number of options available, such as assets, income-generating activities, public services and social safety nets (Ungar 2012). In contrast to when shocks (endogenous or exogenous)occur, households react by using available coping strategies (Ungar 2012). The following are reasons highlighted by the participants, when they sought to explain how they coped with adversity and adapted to life as migrants in South Africa.

\section{Religious Compatibility with Indian Muslim community}

Somali migrants were accustomed to one language, one culture, and one religion in their country, hence on arrival in South Africa they found it difficult to adapt as their culture did not equip them to integrate with other nationalities. Consequently, adapting to the various lifestyles and diversity of the local populations, presented a major challenge for the Somali migrants. The Somali migrants in the Fordsburg/ Mayfair area stated quite categorically that living and integrating with other Somali migrants enabled the resilience that they shared as a community. The support received from the local Indian Muslim community enhanced this resilience and assisted with indigent migrants (Sadouni 2009; Chonka 2017). The participants emphasised the strong ties that 
they shared with the Indian Muslim community in Fordsburg/ Mayfair. Mr. Moosa stated that,

It's Muslim and has an Indian community, and the Indians help me. I feel safe... When you ask the Indians job they going to give you job; we are related because we are Muslims, because we are same religion .... And accommodation, as it is customary in our community to help (Mr. Moosa).

The Fordsburg/ Mayfair Indian Muslim community took it upon themselves to be the guardians of the Somali migrants and welcomed them into the local mosque. There, it was possible for Somali migrants where to share their challenges with fellow Muslims. Mr. Abdul and Mr. Dawood confirmed that when Somali migrants were in need, they received assistance from the local Indian Muslims, for example Mrs. Ebrahim said 'When I'm sick they help me lot'.

New migrants who enter South Africa are aware that there is a large Somali migrant population residing in the Fordsburg/ Mayfair area. The migrants who are settled in this area usually welcome new migrants, as mentioned by a number of participants, such as Mr. Mohamed:

Knowing Somalis introduced me to other friends, new friends to meet Somalis, starting with a friend who introduced me to other friends, from Somalia, who are citizens, playing soccer and going to other areas, shops, going with them and playing with them soccer to the mosque and sharing with them when I eat...also tried finding new friends that are living in this area ... Fordsburg/ Mayfair. We knew each other in Somalia, this made me feel comfortable. The mosques help the Somali community in many ways like the....Imam will stand and ask for money for the people who need help, like fifty thousand and even a million rand (Mr. Mohamed).

The majority of the Somali migrants in my study concur that the Muslim religious institutions plays a significant role in their daily lives. As Jinnah (2010) indicates, the location of a mosque served as their compass to Johannesburg. Hence, their religious affiliation played a key role in them choosing to settle in the Fordsburg/ Mayfair area. The participants added that 
their religion and culture enabled them to create a Somali migrant community. In addition, the Indian Muslim community welcomed the Somali migrants and provided a sense of belonging based on shared religious persuasion. Due to the community and the religious persuasion, resilience was built for them to face their challenges in a new location.

\section{Gender Role Adaptation}

There are gender-related aspects for resilience among the Somali migrants that can be identified in the empirical material. The continuous adaptation of gender roles within the family, in response to the husbands' absence, was one of the things that built resilience among the female participants, Fatima a 34-year-old participant with children living in Somalia with her mother maintained 'Male is in authority. He is the head of the household in the family .... He provides'.

There were times when the men had no choice but to take on jobs away from their home. As a result of their absence Somali women took on roles of authority in their households. In this way, certain forms of patriarchal power was transferred to women.

But majority Somalian woman one day get married, they sit at home, they look after the kids, they look after the husband and them self. But like here you cannot sit. Maybe you open a shop, your husband will be selling and few time people get killed. You have to work. You have to learn how to work and you have to survive (Mrs Khan).

According to Al-Sharmani (2016), Kleist (2008) and Jinnah (2013) Somali women are different, in many ways, from other female migrants in South Africa, as they tend to migrate without a male partner and with or without monetary or emotional support from the family. Once they enter South Africa, they engage in and create new social networks that enable better leverage of resource. (Miss Patel \& Mrs Mohammed) explained how they had to work as cooks in the Eastern Cape and Potchefstroom to look after the family.

Somalis woman take care of their children and husband as well. They do tailor; business, and cooking food, not enough, woman does not work in Somalia community. 
One particular example of separation from the spouse is the transformation of the migrant household. The transnational household in some cases strengthens marital and family relations and, in some cases, strains them, one of the women maintained how being away from their husbands, made them feel like a single parent,

Ifeel bad about it, not staying with my husband my children are alone, the children alone, sometime children are fearing the husband. I'm just like a single mother but I'm not single. If I could be single I could be free (Mrs Khan).

Similarly, the female participants in this study felt the strain of taking the responsibility of heading their households as a major responsibility. Mrs Mohammed explained this to me.

He's working in a shop, as a shopkeeper in the location, he's taking three thousand rand a month; I'm staying in a single room with other women, we share a large room with one kitchen and bathroom. I pay two thousand five rand rent a month. The money is not enough for me and my family (Mrs Mohammed).

While the men saw working away from the home as an opportunity for providing for the family, the migrant women saw it as strenuous; this is a direct contrast to their traditional responsibility of staying at home and caring for children. Resilience is displayed with the conflation of values and rituals. In the same way, Al-Sharmani (2010) states that men see having geographically split households as either an opportunity to evade their duties or to take more responsibility. The household disruption reveals the motivation to provide despite the xenophobia and discrimination (Sadouni 2009). Women, on the other hand, find new prospects to access services and to take on decisionmaking roles in households where males are absent by being engaged in trade or continuing their studies (Sharma 2015). The new household pattern also warrants new kinds of networks. In Cairo, Egypt, for example, a family-based network led by females is the main support system used by Somalis (McMichael 2002; Al-Sharmani 2006).

Given this change in roles questions are raised as to why families to urge women to leave Somalia. Al-Sharmani (2006) points out that there are 
three main reasons for migration among Somali women; migration as a means of protection from sexual violence in Somalia, to fuel the mythical notion that women are more likely to be granted asylum than men, and the fact that women are able to find work in the informal economy, particularly in the global recession. In support of the latter, this study shows an adjustment in Somali society where women are not just producers and reproducers of care, but are also beginning to be active participants in the economy of this country. This necessitates their migration to hold their families together in the host country. Resilience becomes the beacon of hope accompanied by religion and spirituality.

\section{Conclusion}

The article highlighted the lived experiences and the resilience of Somali migrants who reside in Fordsburg/ Mayfair, Johannesburg. These migrants came to South Africa because of their desire to have an improved lifestyle for themselves and for their children. Migration is a complicated journey that brings loss, disappointment, and dissatisfaction in life. This article presented some of the complex stressors that Somali migrants experienced in their dayto-day lives in South Africa. The participants experienced challenges, including difficulty accessing public transport during their migration, fear that came with the various discriminatory and criminal offences that were committed against them, non-recognition by the Government officials, language barriers, as well as the loss of family and friends. In addition, they experienced challenges to the traditional roles that they were accustomed to in Somalia. For the Somali migrants the distinction between religion and culture, between community and family are artificial.

However, this article also highlights the strengths and capabilities of these Somalis in the face of discrimination and xenophobia. This article served to enlighten readers about the strategies of adaptation that Somali migrants rely on to ensure their survival, and help us better understand resilience. They combined their resources to deal with the challenges in their lives. The participants revealed how strong and determined they had become as a result of the hardships that they endured en route to and in South Africa and they enriched their communication skills by attempting to improve their English. Xenophobia did not halt their quest for survival, and their resilience was significantly influenced by their sense of community, culture, family, and religion. 
Jennifer R.F. Sigamoney

\section{References}

Abdi, C. 2015. Elusive Jannah: The Somali Diaspora and a Borderless Muslim Identity. Minneapolis and London: University of Minnesota Press.

https://doi.org/10.5749/minnesota/9780816697380.001.0001

Abdi, C. 2014. Threatened Identities and Gendered Opportunities: Somali

Migration to America. Signs: Journal of Women in Culture and Society

39,2:459 - 483.

https://doi.org/10.1086/673380

Adogame, A. \& J. Spickard 2010. Religion Crossing Boundaries:

Transnational Religious and Social Dynamics in Africa and the New

African Diaspora. Leiden \& Boston: Brill.

https://doi.org/10.1163/ej.9789004187306.i-280

Al-Sharmani, M. 2016. Politics and Ethics of Marriage and Family Life among

Transnational Somali Diasporas. Bildhaan: An International Journal of

Somali Studies 16:36 - 48.

Al-Sharmani, M. 2010. Transnational Family Networks in the Somali Diaspora in Egypt: Women's Roles and Differentiated Experiences. Gender, Place \& Culture 17,4:499 - 518.

https://doi.org/10.1080/0966369X.2010.485843

BenEzer, G. \& R. Zetter 2015. Searching for Directions: Conceptual and Methodological Challenges in Researching Refugee Journeys. Journal of Refugee Studies 28, 3:297 - 318.

https://doi.org/10.1093/jrs/feu022

Coy, T. 2017. Xenophobic Times: Muslim Somali Diaspora and the Nature of

Human Rights, Culture, and Identity in the USA. International Journal of Social Sciences 3, 2:856 - 878.

https://doi.org/10.20319/pijss.2017.32.856878

Creswell, J.W. 2014. Qualitative Inquiry: Qualitative Inquiry and Research

Design. $4^{\text {th }}$ Edition. Los Angeles CA: SAGE Publications.

https://www.amazon.com/Qualitative-Inquiry-Research-Design-

Approaches/dp/1412995302

Denzin, N.K. \& Y.S. Lincoln (eds.). 2011. The Sage Handbook of Qualitative

Research. $4^{\text {th }}$ Edition. Thousand Oaks CA: Sage Publications.

https://www.amazon.com/SAGE-Handbook-Qualitative-Research-

Handbooks/dp/1412974178

Derain, J. \& S. Assay 2014. Strong Families around the World: Strengthsbased Research and Perspectives. London: Routledge. 
https://www.amazon.com/Strong-Families-Around-World-Strengths-

Based/dp/0789036045

Douglas, M. 1991. The Idea of a Home: A Kind of Space. Social Research 58: $287-307$.

Ennis, S. 2011. Religion, Spirituality and the Refugee Experience. Doctoral Dissertation, MIT University.

Giorgio, A. 2009. Phenomenology. In Smith, J.A. (eds.): Qualitative Psychology: A Practical Guide to Research Methods. London: Sage.

https://doi.org/10.1093/jrs/15.2.129

Gozdziak, E.M. \& D.J. Shandy 2002. Editorial Introduction: Religion and Spirituality in Forced Migration. Journal for Refugee Studies 15,2:129 135.

Hammond, L. \& A. Lindely 2014. Histories and Contemporary Challenges in Somali Crisis and Mobility. In Lindely, A. (eds.): Crisis and Migration. Abington: Routledge.

https://www.amazon.com/Crisis-Migration-Perspectives-DevelopmentMobilities/dp/0415645026

Hickel, J. 2014. Xenophobia in South Africa: Order, Chaos, and the Moral Economy of Witchcraft. Cultural Anthropology 29,1:103 - 127.

https://doi.org/10.14506/ca29.1.07

Ibrahim, M. 2010 Somali and Global Terrorism: A Growing Connection? Journal of Contemporary African Studies 28,3:283 - 295.

https://doi.org/10.1080/02589001.2010.497350

Ingiriis, M.H. 2016. Many Somalia(s), Multiple Memories: Remembrances as

Present Politics, Past Politics as Remembrances in War-torn Somali Discourses. African Identities 14,4:348 - 369.

https://doi.org/10.1080/14725843.2016.1143804

International Organisation of Migration 2015. World Migration Report. Migrants and Cities: New Partnerships to Manage Mobility. Geneva, Switzerland: IOM.

http://publications.iom.int/system/files/wmr2015 en.pdf

Jinnah, Z. 2010. Making Home in a Hostile Land: Understanding Somali Identity, Integration, Livelihood and Risks in Johannesburg. Journal of Sociology and Social Anthropology 1,1-2:91 - 99.

https://doi.org/10.1080/09766634.2010.11885542

Jinnah, Z. 2013. New Households, New Rules? Examining the Impact of Migration on Somali Family Life in Johannesburg. QScience Proceedings 7. 
Jinnah, Z. 2017. Cultural Causations and Expressions of Distress: A Case Study of Buufis amongst Somalis in Johannesburg. Urban Forum 28,1:111 - 123 .

https://doi.org/10.1007/s12132-016-9283-y

Kabir. N.A. 2014. Young Somalis in Australia, the UK and the USA: An Understanding of their Identity and their Sense of Belonging. Journal of Muslim Minority Affairs 34, 3:259 - 281.

https://doi.org/10.1080/13602004.2014.939556

Kleist, N. 2008. Mobilising 'the Diaspora': Somali Transnational Political

Engagement. Journal of Ethnic and Migration Studies 34,2:307 - 323.

https://doi.org/10.1080/13691830701823855

Langellier, K.M. 2010. Performing Somali Identity in the Diaspora. Cultural Studies 24,1:66 - 94.

https://doi.org/10.1080/09502380903200723

Lopez, K.A. \& D.G. Willis 2004. Descriptive versus Interpretive

Phenomenology: Their Contributions to Nursing Knowledge. Qualitative Health Research 14,5:726 - 735.

https://doi.org/10.1177/1049732304263638

Luthar, S.S. \& D. Cicchetti 2000. The Construct of Resilience: Implications for Interventions and Social Policies. Development and Psychopathology 12,4: $857-885$.

https://doi.org/10.1017/S0954579400004156

McMichael, C. 2002. 'Everywhere is Allah's Place': Islam and the Everyday Life of Somali Women in Melbourne, Australia. Journal of Refugee Studies 15,2:171 - 188.

https://doi.org/10.1093/jrs/15.2.171

Neuman, W.L. 2011. Basics of Social Research: Qualitative and Quantitative Approach. Boston: Allyn \& Bacon.

https://www.amazon.com/Basics-Social-Research-Qualitative-

Quantitative/dp/0205484379

Patton, M.Q. 2002. Qualitative Research and Evaluation Methods. $3^{\text {rd }}$ Edition.

Thousand Oaks, California: Sage Publications.

https://books.google.co.za/books/about/Qualitative Research Evaluatio

n Methods.html?id=FjBw2oi8El4C\&redir esc $=\mathrm{y}$

Pineteh, E.A. 2017. Moments of Suffering, Pain and Resilience: Somali Refugees' Memories of Home and Journeys to Exile. Cogent Social Sciences 3,1. Article 1372848. 
Richardson, G.E. 2002. The Metatheory of Resilience and Resiliency. Journal of Clinical Psychology 58,3:307 - 321.

https://doi.org/10.1002/jclp.10020

Robinson, R.V. 2013. Pathways to Resilience in the Context of Somali Culture and Forced Displacement. Doctoral dissertation. Available from ProQuest Dissertations and Theses database. (UMI No.3591705).

Sadouni, S. 2009. 'God is not Unemployed': Journeys of Somali Refugees in Johannesburg. African Studies 68,2: 235 - 249.

https://doi.org/10.1080/00020180903109615

Settler, FG. 2018. A Postcolonial Perspective of Religion and Migration. In Turner, B. \& T. Wyller (eds.): Borderland Religion. Abingdon: Routledge Press.

https://doi.org/10.4324/9781351056946-8

Shaffer, M. 2012. This is South Africa, Not Somalia: Negotiating Gender Relations in Johannesburg's 'Little Mogadishu'. Doctoral dissertation, Ohio State University.

Sharma, B. 2015. A Study of Resilience and Social Problem Solving in Urban Indian Adolescents. International Journal of Indian Psychology 2,3:70 85.

Sigamoney, J. 2017. The Resilience of a Somali Community in Johannesburg. Mail \& Guardian.

Sigamoney, R.F., 2016. The Reasons that Promote the Resilience of a Somali Community Residing in Fordsburg/ Mayfair, Johannesburg. Doctoral dissertation. University of South Africa (Unisa).

Ungar, M. 2012. Social Ecologies and their Contribution to Resilience. In Ungar, M. (eds.): The Social Ecology of Resilience. New York: Springer. https://doi.org/10.1007/978-1-4614-0586-3_2 https://doi.org/10.1007/978-1-4614-0586-3

UNHCR 2018 UNHCR Guidelines on Determining the Best Interests of the Child. Available at:

https://www.refworld.org/docid/48480c342.html

(Accessed on 4 December 2018.)

Vertovec, S. 2009. Transnationalism. New York: Routledge.

https://doi.org/10.4324/9780203927083

Wellman, C.H. \& P. Cole 2011. Debating the Ethics of Immigration: Is there a Right to Exclude? Oxford: Oxford University Press. https://doi.org/10.1093/acprof:osobl/9780199731732.001.0001 
Jennifer R.F. Sigamoney

Jennifer R.F. Sigamoney Research Psychologist PhD Student Practical Theology North West University (Potchefstroom) Jsigamoney1@gmail.com 